\title{
A Study on Dynamic Response of Tunnel Blasting Beneath Surface Buildings
}

\author{
chen huang $^{1}$, youyi zhang ${ }^{1}$, and Jun Zhao ${ }^{2}$ \\ ${ }^{1}$ Southwest University of Science and Technology \\ ${ }^{2}$ Southwest Jiaotong University
}

May 31, 2021

\begin{abstract}
In order to study the dynamic response of adjacent buildings in the process of tunnel blasting excavation, taking Yangjia tunnel blasting through a five-story frame structure residential building as an example, the propagation law of blasting seismic wave was analyzed by using HHT method through on-site blasting monitoring. Then, the ALE algorithm in ANSYS/LS-DYNA software was used to establish a three-dimensional numerical model based on the surrounding rock-cutting section-structure coupling to study the dynamic response of adjacent buildings under the blasting vibration of tunnel. The results show that the HHT analysis method can clearly describe the energy distribution of vibration signals in the time and frequency domain. The energy carried by the blasting vibration signal is corresponding to the detonating section, and the maximum energy appears in the cutting section, which further verifying that the vibration effect caused by the cutting hole blasting is the strongest. In the process of tunnel blasting, the dynamic responses of beams, columns and exterior walls of adjacent buildings are not consistent and show different variation rules along the height direction. In addition, the stress centralization mainly occurs in the exterior wall of the building, the joint of the exterior wall and the column, the joint of the exterior wall and the beam, and the joint of the exterior wall and the floor and other non-weight bearing area, indicating that these parts are more likely to damage and crack in the process of tunnel blasting.
\end{abstract}

\section{Hosted file}

manuscript.docx available at https://authorea.com/users/417025/articles/524279-a-study-ondynamic-response-of-tunnel-blasting-beneath-surface-buildings 